\title{
Euchrestaflavanone A can attenuate thrombosis through inhibition of collagen-induced platelet activation
}

\author{
Jung-Hae Shin ${ }^{1}$ (D) $\cdot$ Hyuk-Woo Kwon ${ }^{2}$ (D)
}

Received: 22 September 2020 / Accepted: 19 October 2020 / Published Online: 31 December 2020

(C) The Korean Society for Applied Biological Chemistry 2020

\begin{abstract}
Euchrestaflavanone A (EFA) is a flavonoid found in the root bark of Cudrania tricuspidata. C. tricuspidata extract, widely used throughout Asia in traditional medicine, has been investigated phytochemically and biologically and is known to have anti-obesity, anti-inflammatory, and anti-tumor effects. It has been reported that $C$. tricuspidata extract also possesses antiplatelet effects; however, the mechanism of its anti-platelet and anti-thrombotic activities is yet to be elucidated. In this study, we investigated the effects of EFA on the modulation of platelet function using collagen-induced human platelets. Our results showed that EFA markedly inhibited platelet aggregation. Furthermore, it downregulated glycoprotein IIb/IIIa ( $\alpha \mathrm{IIb} / \beta 3$ )mediated signaling events, including platelet adhesion, granule secretion, thromboxane $\mathrm{A}_{2}$ production, and clot retraction, but upregulated the cyclic adenosine monophosphate-dependent pathway. Taken together, EFA possesses strong anti-platelet and anti-thrombotic properties and is a potential therapeutic drug candidate to prevent platelet-related thrombosis and cardiovascular disease.
\end{abstract}

Keywords $\alpha \mathrm{IIb} / \beta 3$ affinity $\cdot \mathrm{Ca}^{2+}$ mobilization $\cdot \mathrm{cAMP}$ and cGMP · Clot retraction · Euchrestaflavanone A

Hyuk-Woo Kwon $(\square)$

E-mail:kwonhw@kdu.ac.kr

${ }^{1}$ Department of Biomedical Laboratory Science, Catholic Kwandong University, Gangneung 25601, Republic of Korea

${ }^{2}$ Department of Biomedical Laboratory Science, Far East University, Eumseong 27601, Republic of Korea

This is an Open Access article distributed under the terms of the Creative Commons Attribution Non-Commercial License (http://creativecommons. org/licenses/by-nc/3.0/) which permits unrestricted non-commercial use, distribution, and reproduction in any medium, provided the original work is properly cited.

\section{Introduction}

In normal circulation, collagen fibers cannot bind to platelets. However, when endothelial walls are injured, exposed collagen fibers can bind to integrin $\alpha 2 \beta 1$ and glycoprotein VI on platelet receptors, leading to platelet activation. After activation, phospholipase $\mathrm{C} \gamma_{2}$ within the cytosol hydrolyzes phosphatidylinositol 4,5bisphosphate into inositol diacylglycerol and 1,4,5-trisphosphate $\left(\mathrm{IP}_{3}\right)$, which then mobilizes calcium from the endoplasmic reticulum [1,2]. These signaling events in activated platelets cause conformational changes in glycoprotein IIb/IIIa (integrin $\alpha \mathrm{IIb} / \beta 3$ ), leading to thrombus formation and platelet-mediated clot retraction [3]. Therefore, platelets are an essential factor for hemostasis, while simultaneously posing a risk for thrombosis. The underlying cause of cardiovascular disease (CVD) is pathological platelet overactivity, leading to thrombosis [4]. Pharmacological platelet suppression effectively reduces thrombosis, and many drugs are available for preventing CVD, with numerous anti-platelet and anti-thrombotic drugs being discovered. Nonetheless, these drugs have been largely unable to effectively decrease mortality rates [5].

Cudrania tricuspidata is widespread throughout Asia and used in ethnomedicine, particularly against eczema, mumps, and tuberculosis [6]. It has been reported that C. tricuspidata extracts have various physiological activities, including anti-inflammatory, anti-diabetic, neuroprotective, anti-obesity, anti-tumor, and anticoagulant activities [7]. We have previously reported the antiplatelet effects of steppogenin and isoderrone isolated from $C$. tricuspidata on collagen-induced human platelets [8,9]. However, C. tricuspidata contains numerous components; thus, herein, we studied a new candidate, euchrestaflavanone A (EFA), for its antiplatelet effects. 


\section{Materials and Methods}

\section{Chemicals and reagents}

ChemFaces (Wuhan, China) supplied EFA. The Chrono-Log corporation (Havertown, PA, USA) supplied platelet collagen. Cayman Chemical (Ann Arbor, MI, USA) supplied the cAMP EIA and thromboxane $\mathrm{B}_{2}$ assay kits. Cell Signaling (Beverly, MA, USA) supplied the lysis buffer and antibodies against phosphovasodilator-stimulated phosphoprotein (VASP), phospho-inositol3-phosphate receptor type I ( $\left.\mathrm{IP}_{3} \mathrm{RI}\right)$, phospho-cytosolic phospholipase $\mathrm{A}_{2}\left(\mathrm{cPLA}_{2}\right)$, phospho-p38 mitogen-activated protein kinase $\left(\mathrm{p} 38^{\mathrm{MAPK}}\right)$, phospho-Akt, and â-actin, and anti-rabbit secondary antibodies. Invitrogen (Eugene, OR, USA) provided Fura 2-AM(2-acetoxymethyl-) and Alexa Fluor 488-conjugated fibrinogen. The fibronectin-coated cell adhesion kit was procured from Cell Biolabs (San Diego, CA, USA). The serotonin enzyme-linked immunosorbent assay (ELISA) kit was purchased from Labor Diagnostika Nord GmbH \& Co. (Nordhorn, Germany).

\section{Preparation of human platelet suspension}

The human platelet-rich plasma was procured from the Korean Red Cross Blood Center (Suwon, Korea), and study protocols were approved by the Public Institutional Review Board at the National Institute for Bioethics Policy (Seoul, Republic of Korea; PIRB-P01-201812-31-007). The platelet-rich plasma was centrifuged for $10 \mathrm{~min}$ at $1300 \times \mathrm{g}$ and the pellet was washed twice using washing buffer ( $\mathrm{pH}$ 6.5) and re-suspended in suspension buffer (pH 6.9) at room temperature according to the protocol published in a previous study [10]. The platelet suspension concentration was adjusted to $5 \times 10^{8} / \mathrm{mL}$.

\section{Platelet aggregation}

For platelet aggregation, human platelet suspensions $\left(10^{8} / \mathrm{mL}\right)$ were pre-incubated for $3 \mathrm{~min}$ in the presence or absence of EFA ( 25 to $150 \mu \mathrm{M}$ ) along with $2 \mathrm{mM} \mathrm{CaCl} 2$ at $37{ }^{\circ} \mathrm{C}$, followed by stimulation with agonists. Collagen $(2.5 \mu \mathrm{g} / \mathrm{mL})$ triggers full platelet aggregation and was used as agonists for aggregation. The aggregation assay was conducted for $5 \mathrm{~min}$ under continuous stirring. An increase in light transmission converted into the platelet aggregation rate (\%). A $0.1 \%$ dimethyl sulfoxide solution was used to dissolve the EFA.

\section{Cytotoxicity assay}

Cytotoxicity of EFA was examined by quantifying lactate dehydrogenase (LDH) leakage from the cytosol of platelets. Human platelet suspensions $\left(10^{8} / \mathrm{mL}\right)$ were incubated with different concentrations of EFA (25 to $150 \mu \mathrm{M})$ for $2 \mathrm{~h}$ and centrifuged for $2 \mathrm{~min}$ at $12,000 \times \mathrm{g}$. The supernatant was used to detect cytotoxic effects using an ELISA reader (TECAN, Salzburg, Austria).

\section{Intracellular calcium concentration}

The Fura 2-AM $(5 \mu \mathrm{M})$ and PRP mixture was pre-incubated at $37^{\circ} \mathrm{C}$ for $60 \mathrm{~min}$, and then the human platelet suspension $\left(10^{8} /\right.$ $\mathrm{mL}$ ) was washed with washing buffer. The platelets were then suspended in suspending buffer, pre-incubated with or without EFA for $3 \mathrm{~min}$ at $37^{\circ} \mathrm{C}$, and stimulated with $2.5 \mu \mathrm{g} / \mathrm{mL}$ collagen in the presence of $2 \mathrm{mM} \mathrm{CaCl}_{2}$. To calculate the $\left[\mathrm{Ca}^{2+}\right]_{\mathrm{i}}$ values, Fura 2-AM fluorescence was measured according to the Grynkiewicz method [11] using a spectrofluorometer (Hitachi F2700; Tokyo, Japan).

\section{Measurement of thromboxane $B_{\mathbf{2}}$}

Since thromboxane $\mathrm{A}_{2}\left(\mathrm{TXA}_{2}\right)$ is unstable and transforms into thromboxane $\mathrm{B}_{2}\left(\mathrm{TXB}_{2}\right)$ quickly, $\mathrm{TXA}_{2}$ generation was measured by detecting $\mathrm{TXB}_{2}$ production. After platelet activation, the reaction was stopped by adding $0.2 \mathrm{mM}$ indomethacin with $5 \mathrm{mM}$ EDTA. $\mathrm{TXB}_{2}$ levels were measured using an ELISA reader (TECAN, Salzburg, Austria) and a $\mathrm{TXB}_{2}$ ELISA kit.

\section{Measurement of serotonin}

Human platelet suspensions $\left(10^{8} / \mathrm{mL}\right)$ were pre-incubated for 3 min at $37^{\circ} \mathrm{C}$ with EFA and then stimulated with $2.5 \mu \mathrm{g} / \mathrm{mL}$ collagen in the presence of $2 \mathrm{mM} \mathrm{CaCl}{ }_{2}$ to terminate serotonin release, followed by centrifugation $(250 \mathrm{~g})$. The supernatant was used for detecting serotonin release with an ELISA reader (TECAN, Salzburg, Austria) using a serotonin ELISA kit.

\section{Immunoblotting}

The platelets were aggregated for $5 \mathrm{~min}$ and stopped by adding lysis buffer. The protein concentration in the platelet lysates were calculated using a bicinchoninic acid protein assay kit (Pierce Biotechnology; IL, USA). For Western blotting, $15 \mu \mathrm{g}$ proteins from the platelet lysates were separated using SDS-PAGE (8\%) and transferred onto PVDF membranes, which were then probed with the indicated primary $(1: 1,000)$ and secondary antibodies $(1: 10,000)$. The resulting bands were analyzed using the Quantity One, Ver. 4.5 (BioRad; Hercules, CA, USA).

\section{Measurement of fibrinogen binding to $\alpha \mathrm{II} b / \beta 3$}

Human platelet suspensions $\left(10^{8} / \mathrm{mL}\right)$ were incubated with EFA (25 to $150 \mu \mathrm{M}$ ) and treated with $30 \mu \mathrm{g} / \mathrm{mL}$ Alexa Fluor 488conjugated fibrinogen at $37^{\circ} \mathrm{C}$ for $5 \mathrm{~min}$. The interaction between platelet integrin and Alexa Fluor 488-conjugated human fibrinogen was stopped by adding $0.5 \%$ paraformaldehyde in cold PBS. All procedures were conducted in the dark. The binding of fibrinogen to integrin $\alpha \mathrm{IIb} / \beta 3$ was examined by quantifying the fluorescence of fibrinogen using flow cytometry (BD Biosciences; San Jose, CA, USA), and data were analyzed using CellQuest software (BD Biosciences). 


\section{Fibronectin adhesion}

Human platelet suspensions $\left(10^{8} / \mathrm{mL}\right)$ were pre-incubated with EFA ( 25 to $150 \mu \mathrm{M}$ ) and $2 \mathrm{mM} \mathrm{CaCl}_{2}$ for $1 \mathrm{~h}$ at $37^{\circ} \mathrm{C}$ in the presence of $2.5 \mu \mathrm{g} / \mathrm{mL}$ collagen, washed 5 times with PBS, and incubated with cell stain solution for $10 \mathrm{~min}$. The extraction solution was added after washing with PBS once to detach the adhesive platelet plaque from the fibronectin-coated well. Each sample was examined by measuring the absorbance using an ELISA reader (TECAN, Salzburg, Austria). Bovine serum albumin coated wells were used as a negative control.

Measurement of cyclic adenosine monophosphate (cAMP) and cyclic guanosine monophosphate (cGMP) levels

Washed human platelets $\left(10^{8} / \mathrm{mL}\right)$ were pre-incubated for $3 \mathrm{~min}$ at $37{ }^{\circ} \mathrm{C}$ with or without EFA $(25$ to $150 \mu \mathrm{M})$ in the presence of $2 \mathrm{mM} \mathrm{CaCl}_{2}$, and then stimulated with $2.5 \mu \mathrm{g} / \mathrm{mL}$ collagen for $5 \mathrm{~min}$ for platelet aggregation. The aggregation was terminated by adding $80 \%$ ice-cold ethanol. The cAMP and cGMP levels were measured using an EIA kit and an ELISA reader (TECAN, Salzburg, Austria).

\section{Platelet-mediated fibrin clot retraction}

Human platelet-rich plasma $(300 \mu \mathrm{L})$ was poured into a polyethylene tube and pre-incubated in the presence or absence of various concentrations of EFA $(25$ to $150 \mu \mathrm{M})$ for $15 \mathrm{~min}$ at $37^{\circ} \mathrm{C}$. The clot retraction was triggered by adding $0.05 \mathrm{U} / \mathrm{mL}$ thrombin. The images of fibrin clots were captured using a digital camera at 15 min intervals. Image J Software was used to calculate the clot area (v1.46, National Institutes of Health; USA).

\section{Statistical analyses}

Experimental data are presented as the mean \pm standard deviation included with various numbers of observations. To determine major differences among groups, analysis of variance (ANOVA) was performed followed by the Tukey-Kramer method. SPSS 21.0.0.0 software (SPSS; Chicago, IL, USA) was employed for statistical analysis, and $p<0.05$ was considered statistically significant.

\section{Results}

Effects of EFA on human platelet aggregation and cytotoxicity C. tricuspidata is a perennial plant of the family Moraceae, and its roots, leaves, bark, stems, and fruit contain diverse phytochemicals. Among various phytochemicals, xanthones and flavonoids are the major constituents of $C$. tricuspidata. We searched for a new substance and investigated whether EFA (MW 408.49) (Fig. 1A) has an anti-platelet effect. To determine anti-platelet effects, 2.5 $\mu \mathrm{g} / \mathrm{mL}$ collagen was used for the optimum aggregation of human platelets (Fig. 2A). However, collagen-induced platelets treated with $25,50,100$, and $150 \mu \mathrm{M}$ EFA inhibited dose-dependently

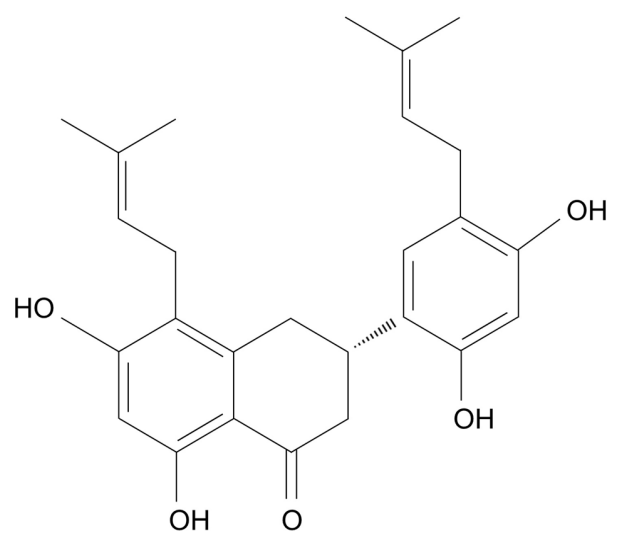

Fig. 1 Chemical structure of euchrestaflavanone A (EFA)

and the half maximal inhibitory concentration $\left(\mathrm{IC}_{50}\right)$ was $49.5 \mu \mathrm{M}$ (Fig. 2A, B). To investigate the cytotoxicity of EFA, we treated the platelets with $25-150 \mu \mathrm{M}$ EFA, which did not affect LDH release (Fig. 2C).

Effects of EFA on $\left[\mathrm{Ca}^{2+}\right]_{i}$ mobilization, serotonin secretion, and $I_{3} R I$ phosphorylation

Intracellular $\left(\left[\mathrm{Ca}^{2+}\right]_{i}\right)$ is an essential factor for platelet activation; thus, we focused on the effect of EFA on $\left[\mathrm{Ca}^{2+}\right]_{\mathrm{i}}$ mobilization. As shown in Fig. 3A, collagen elevated $\left[\mathrm{Ca}^{2+}\right]_{i}$ levels from $110.2 \pm$ $0.7 \mathrm{nM}$ to $770.5 \pm 6.5 \mathrm{nM}$. However, $25-150 \mu \mathrm{M}$ EFA reduced the increased $\left[\mathrm{Ca}^{2+}\right]_{i}$ levels dose-dependently. Intracellular calcium level is related to granule release; thus, we investigated whether EFA is involved in granule release from platelets. As shown in Fig. 3B, collagen-stimulated serotonin secretion was inhibited by 25-150 $\mu \mathrm{M}$ EFA dose-dependently. To confirm the effect of EFA on granule release, we investigated the associated signaling molecule, inositol 1,4,5-triphosphate receptor type I ( $\left.\mathrm{IP}_{3} \mathrm{RI}\right)$, which regulates $\left[\mathrm{Ca}^{2+}\right]_{\mathrm{i}}$ mobilization. As shown in Fig. $3 \mathrm{C}$, collagen increased $\mathrm{IP}_{3} \mathrm{RI}$ phosphorylation was increased by EFA (25 to $150 \mu \mathrm{M})$.

Effects of EFA on $\left[\mathrm{Ca}^{2+}\right]_{i}$ mobilization and $\mathrm{CPLA}_{2}$ and p38 $^{\text {MAPK }}$ dephosphorylation

We next investigated whether EFA is involved in the inhibition of $\mathrm{TXA}_{2}$ production to attenuate collagen-induced human platelet aggregation. Collagen-stimulated human platelet produced $\mathrm{TXA}_{2}$ (determined as $\mathrm{TXB}_{2}$ ) from $1.5 \pm 0.2 \mathrm{nM}$ to $55.8 \pm 4.8 \mathrm{ng} / 10^{8}$. However, 25-150 $\mu \mathrm{M}$ EFA inhibited $\mathrm{TXA}_{2}$ production dosedependently (Fig. 4A). We next investigated the $\mathrm{TXA}_{2}$ associated signaling molecules, $\mathrm{cPLA}_{2}$ and $\mathrm{p} 38^{\mathrm{MAPK}}$. While $2.5 \mu \mathrm{g} / \mathrm{mL}$ collagen elevated $\mathrm{CPLA}_{2}$ and $\mathrm{p} 38^{\mathrm{MAPK}}$ phosphorylation, 25-150 iM EFA inhibited $\mathrm{CPLA}_{2}$ and $\mathrm{p} 38^{\mathrm{MAPK}}$ phosphorylation dosedependently (Fig. 4B, C). These results suggest that the inhibition of $\mathrm{TXA}_{2}$ production by EFA is due to $\mathrm{CPLA}_{2}$ and $\mathrm{p} 38^{\mathrm{MAPK}}$ dephosphorylation. 

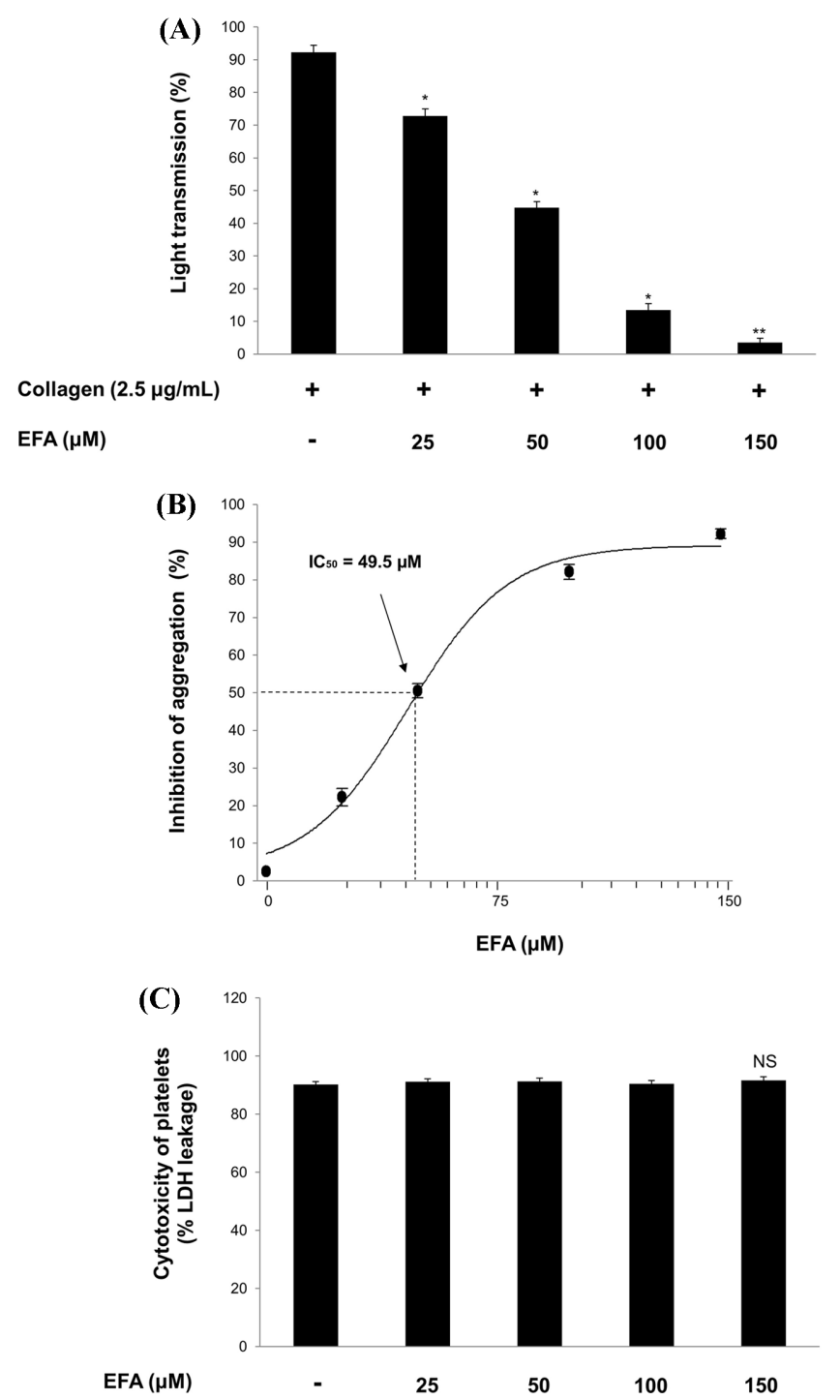

Fig. 2 Effects of EFA on platelet aggregation, half maximal inhibitory concentration, and cytotoxicity (A) Effect of EFA on collagen-induced human platelet aggregation. (B) Half maximal inhibitory concentration $\left(\mathrm{IC}_{50}\right)$ value of EFA in collagen-induced human platelet aggregation. $(\mathrm{C})$ Effect of EFA on cytotoxicity. Platelet aggregation and cytotoxicity were carried out as described in "Materials and Methods" section. The data are expressed as the mean \pm standard deviation $(\mathrm{n}=4) .{ }^{*} p<0.05, * * p<0.01$ versus each agonist-stimulated human platelets. NS, not significant

\section{Effects of EFA on fibrinogen binding to $\alpha \mathrm{IIb} / \beta 3$ and fibronectin adhesion}

We then investigated $\alpha \mathrm{Ilb} / \beta 3$ activation through fibrinogen binding to $\alpha \mathrm{Ilb} / \beta 3$. Collagen elevated the binding of fibrinogen to $\alpha \mathrm{Ilb} / \beta 3$ from $3.5 \pm 1.2 \%$ to $81.8 \pm 2.1$ (Fig. $5 \mathrm{~A}, \mathrm{~B}$ ). However, EFA attenuated fibrinogen interaction with $\alpha \mathrm{IIb} / \beta 3$ dose-dependently (Fig. 5A, B). Since $\alpha \mathrm{IIb} / \beta 3$ also serves as a fibronectin binding molecule, we investigated fibronectin adhesion and found that 25 $150 \mu \mathrm{M}$ EFA inhibited fibronectin adhesion dose-dependently (Fig. 5C).
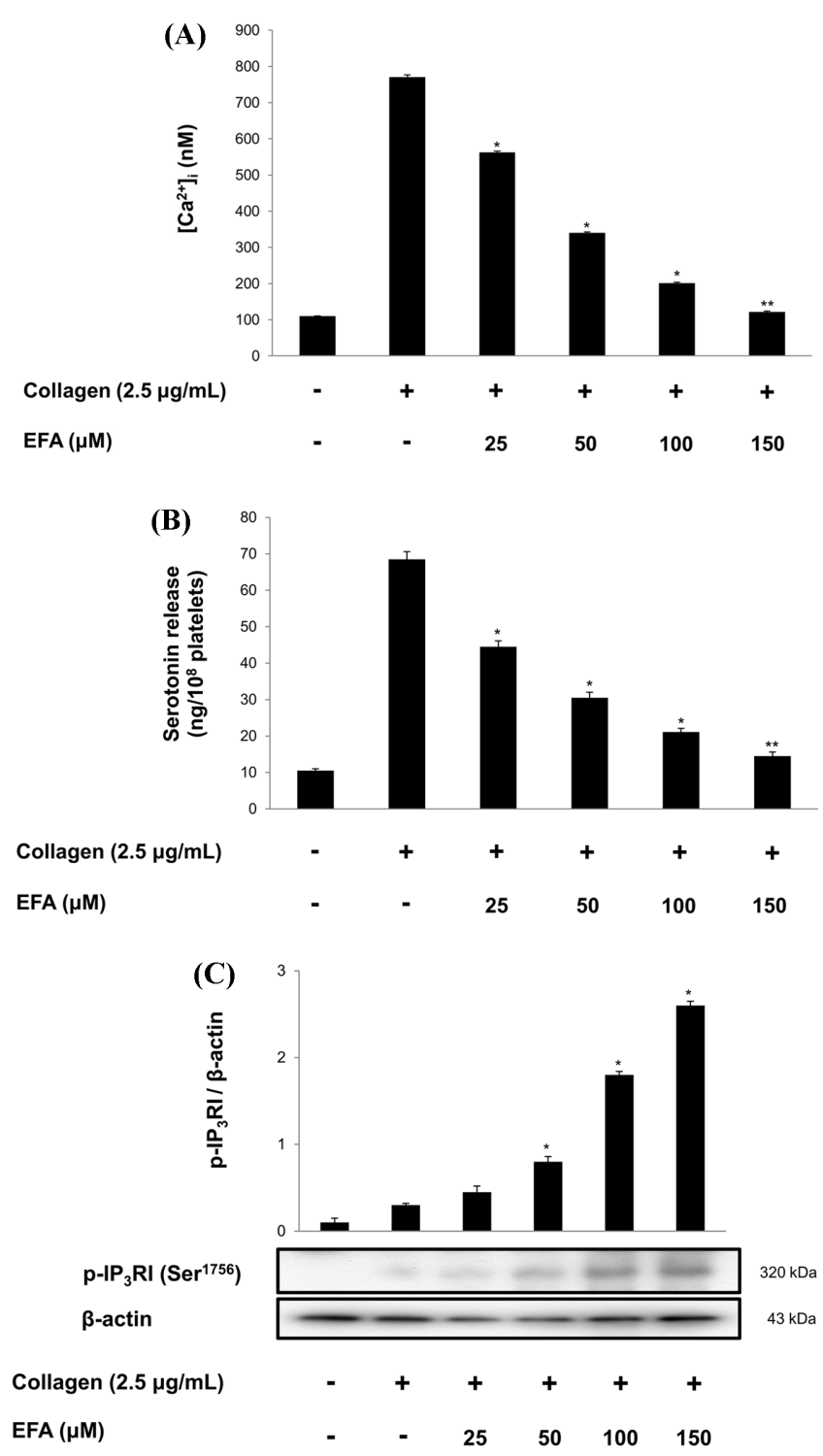

Fig. 3 Effects of EFA on $\left[\mathrm{Ca}^{2+}\right]_{i}$ mobilization, Serotonin release and $\mathrm{IP}_{3} \mathrm{RI}$ phosphorylation (A) Effect of EFA on collagen-induced $\left[\mathrm{Ca}^{2+}\right]_{\mathrm{i}}$ mobilization. (B) Effect of EFA on collagen-induced serotonin release. (C) Effect of EFA on collagen-induced $\mathrm{IP}_{3} \mathrm{RI}\left(\mathrm{Ser}^{1756}\right)$ phosphorylation. Measurement of $\left[\mathrm{Ca}^{2+}\right]_{\mathrm{i}}$ mobilization, serotonin release Western blot was performed as described in "Materials and Methods" section. The data are expressed as the mean \pm standard deviation $(\mathrm{n}=4) .{ }^{*} p<0.05,{ }^{* *} p<0.01$ versus the collagen-stimulated human platelets

\section{Measurement of VASP- and Akt-phosphorylation and cyclic nucleotides}

Phosphorylated VASP is known to suppress $\alpha \mathrm{IIb} / \beta 3$ activation, and phosphorylated Akt is known to increase $\alpha \mathrm{IIb} / \beta 3$ activation. Thus, we examined whether EFA affects VASP- and Aktphosphorylation. EFA strongly phosphorylated VASP at Ser ${ }^{157}$ (Fig. 6A) and dephosphorylated Akt at $\operatorname{Ser}^{473}$ (Fig. 6B). We further investigated the effect of EFA on cAMP and cGMP production in platelets and found that EFA elevated cAMP production dose- 

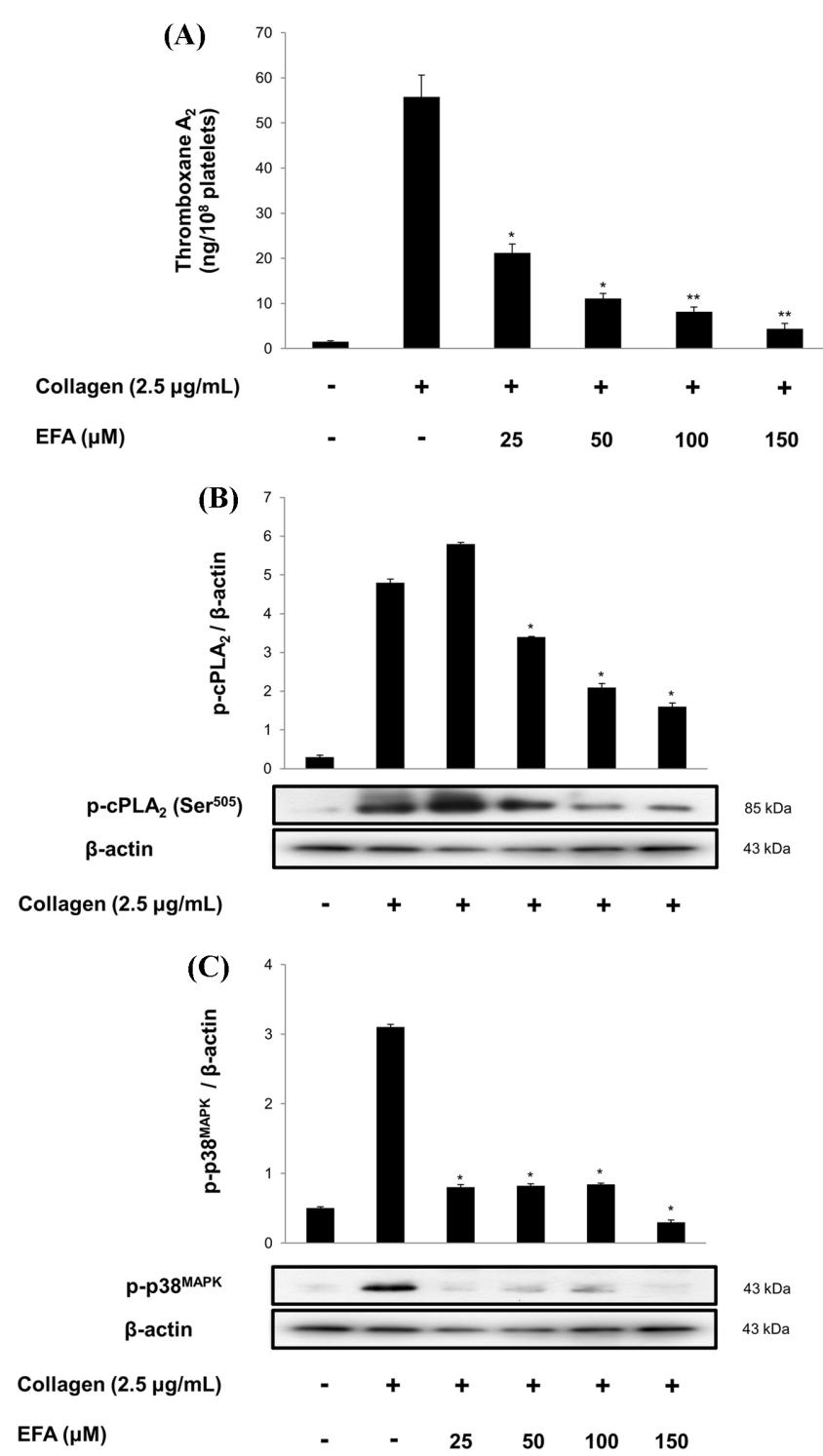

Fig. 4 Effects of EFA on $\mathrm{TXA}_{2}$ generation and $\mathrm{CPLA}_{2}$ and $\mathrm{p} 38$ MAPK phosphorylation. (A) Effects of EFA on collagen-induced $\mathrm{TXA}_{2}$ generation. (B) Effect of EFA on collagen-induced $\mathrm{CPLA}_{2}\left(\mathrm{Ser}^{505}\right)$ phosphorylation. (C) Effect of EFA on collagen-induced p38 $8^{\mathrm{MAPK}}$ phosphorylation. Measurement of $\mathrm{TXA}_{2}$ generation and Western blot was performed as described in "Materials and Methods" section. The data are expressed as the mean \pm standard deviation $(\mathrm{n}=4) .{ }^{*} p<0.05, * * p<0.01$ versus the collagen-stimulated human platelets

dependently (Fig. 6C), but did not increase cGMP production (data not shown).

\section{Effects of EFA on clot retraction}

Activated integrin $\alpha \mathrm{II} / \beta 3$ activates the signaling pathway that triggers fibrin clot retraction. Therefore, we investigated the inhibitory action of EFA on fibrin clot retraction. As shown in Fig. 7A, thrombin-induced fibrin clot formation contracted by $80.4 \%$ compared with that in unstimulated platelet-rich plasma. However, thrombin-stimulated contraction was dose-dependently delayed by
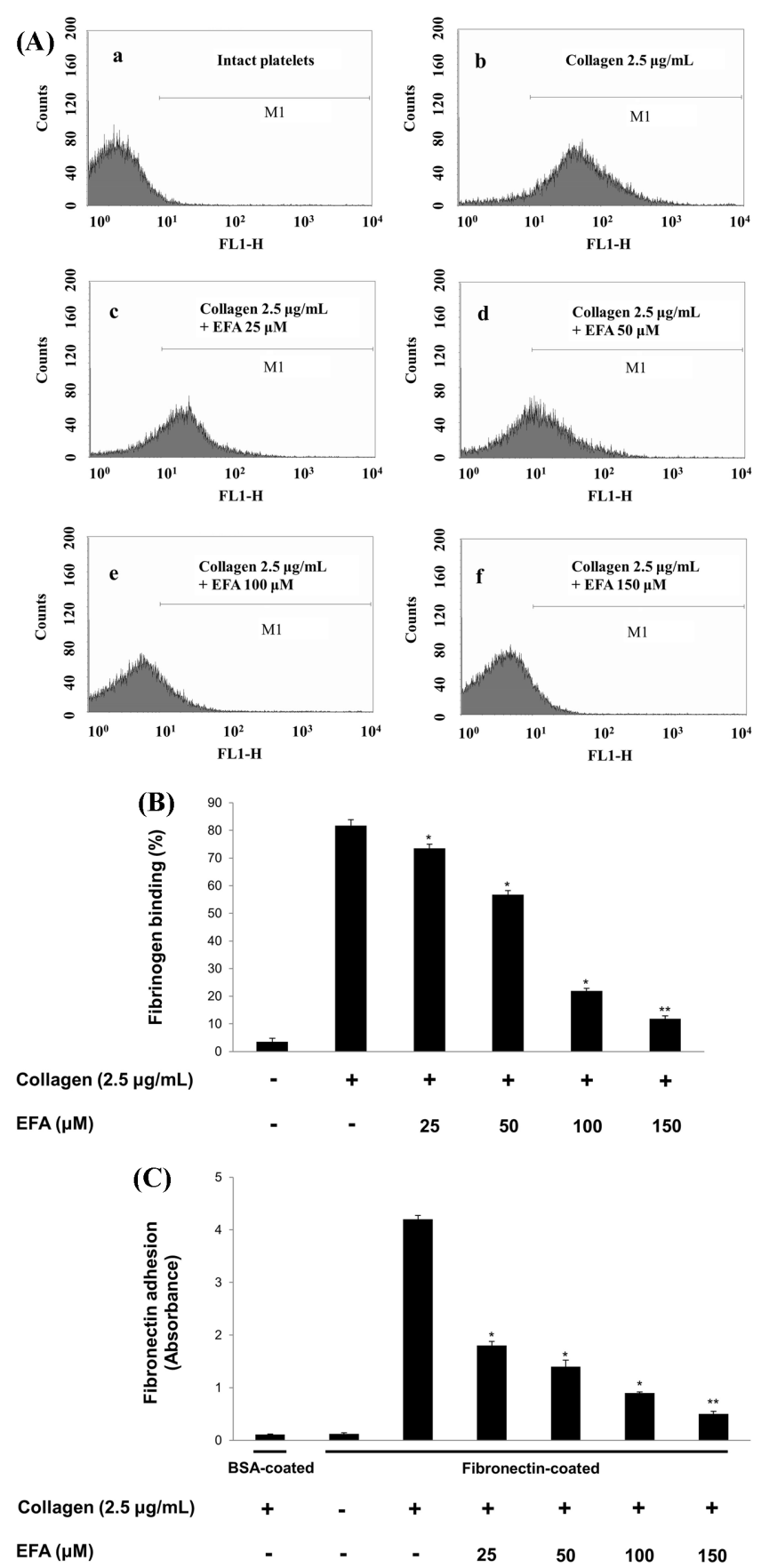

Fig. 5 Effects of EFA on fibrinogen binding to $\alpha I I b / \beta 3$ and Fibronectin adhesion (A) The flow cytometry histograms on fibrinogen binding. (B) Effects of EFA on collagen-induced fibrinogen binding (\%). (C) Effects of EFA on collagen-induced fibronectin adhesion. Measurement of fibrinogen binding and fibronectin adhesion was carried out as described in "Materials and Methods" section. The data are expressed as the mean \pm standard deviation $(\mathrm{n}=4) .{ }^{*} p<0.05, * * p<0.01$ versus the collagenstimulated human platelets

25-150 $\mu \mathrm{M}$ EFA (Fig. 7B). Y27632 $(5 \mu \mathrm{M})$, a positive control, delayed fibrin clot formation by $37.0 \%$ compared with unstimulated platelet-rich plasma. 

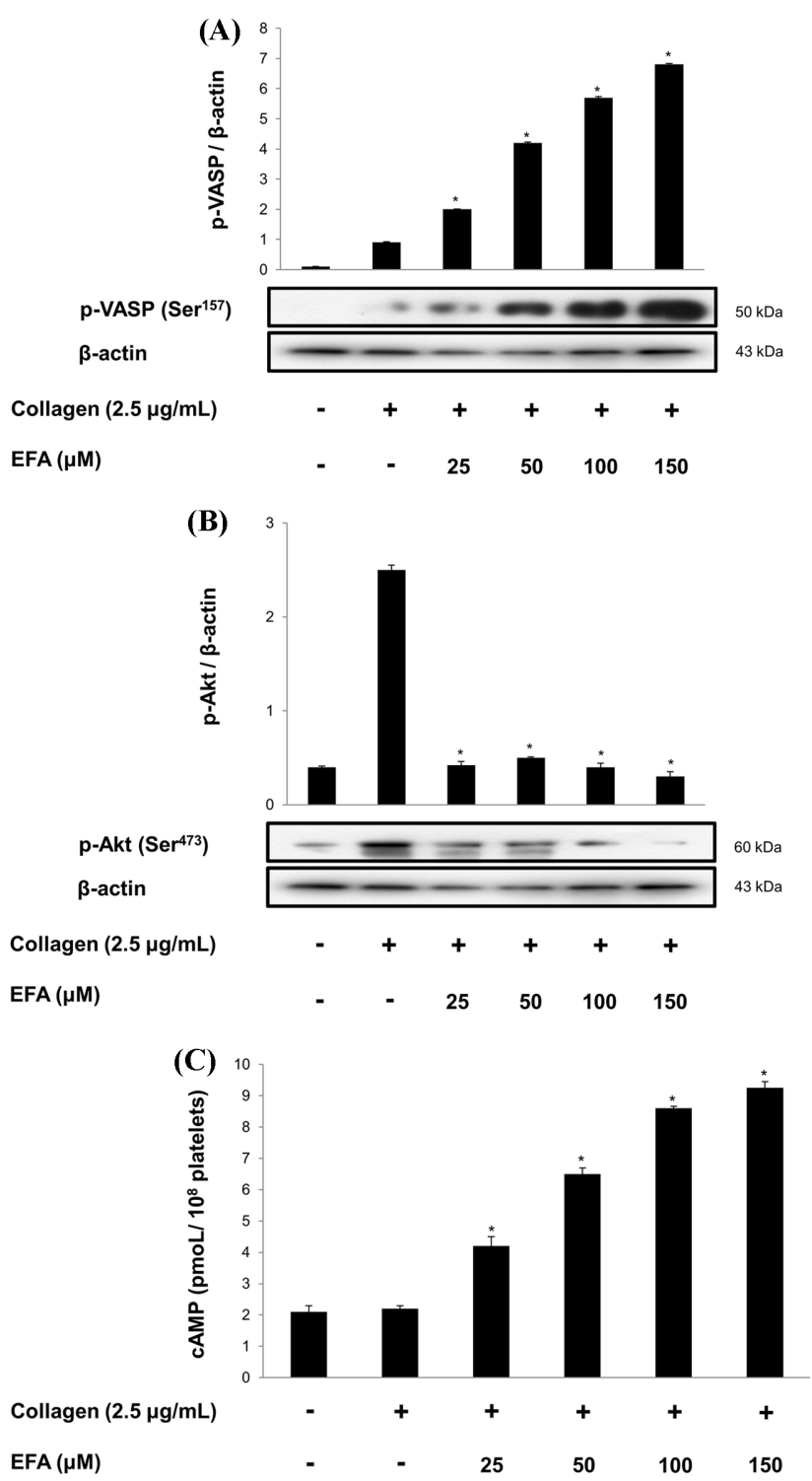

Fig. 6 Effects of EFA on VASP, Akt phosphorylation and cAMP. (A) Effect of EFA on collagen-induced VASP $\left(\mathrm{Ser}^{157}\right)$ phosphorylation. (B) Effect of EFA on collagen-induced Akt $\left(\mathrm{Ser}^{473}\right)$ phosphorylation. (C) Effect of EFA on collagen-induced cAMP production. Measurement of Western blot and cAMP level was performed as described in "Materials and Methods" section. The data are expressed as the mean \pm standard deviation $(\mathrm{n}=4) .{ }^{*} p<0.05,{ }^{* *} p<0.01$ versus the collagen-stimulated human platelets

\section{Discussion}

Various agonists induce platelet-mediated hemostatic plaque by triggering granule secretion, platelet activation, and platelet aggregation. These agonists or adhesive proteins cause inside-out signaling pathways, which involve conformational changes in integrin $\alpha \mathrm{Ilb} / \beta 3$ structure and modulate fibrinogen binding to integrin. $\left[\mathrm{Ca}^{2+}\right]_{\mathrm{i}}$ mobilization is the most critical event in the inside-out signaling pathway. $\mathrm{IP}_{3} \mathrm{RI}$, located on the endoplasmic
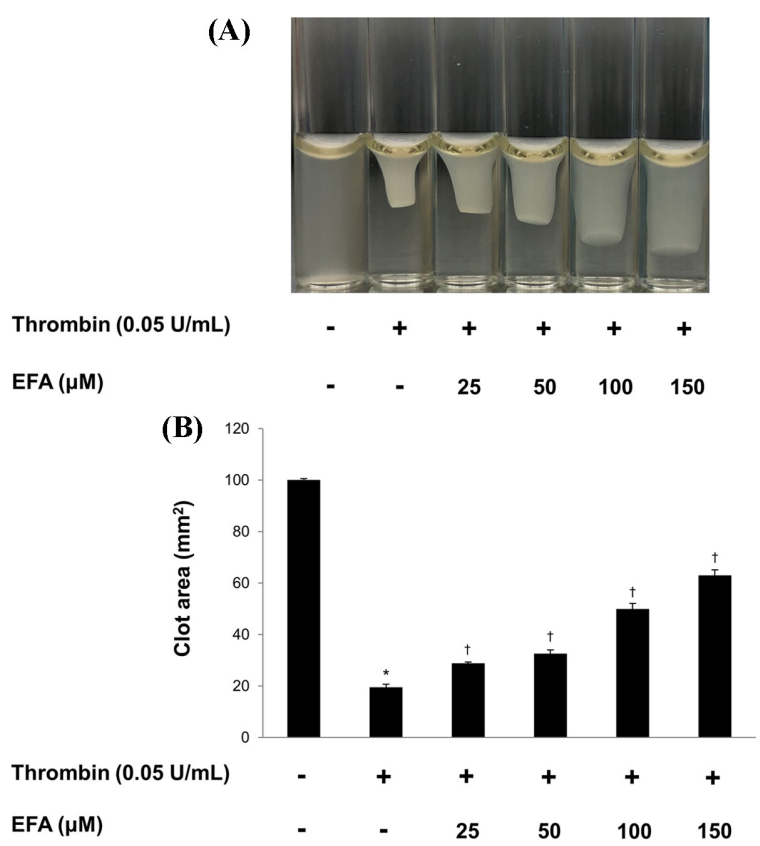

Fig. 7 Effects of EFA on fibrin clot retraction. (A) Photographs of fibrin clot (B) Effects of EFA on thrombin-retracted fibrin clot (\%). Quantification of fibrin clot retraction was performed as describe in "Materials and Methods" section. The data are expressed as the mean \pm standard deviation $(\mathrm{n}=4) .{ }^{*} p<0.05$ versus the unstimulated human PRP, ${ }^{\dagger} p<0.05$ versus the thrombin-stimulated human PRP

reticulum surface, induces $\left[\mathrm{Ca}^{2+}\right]_{\mathrm{i}}$ mobilization by binding with inositol 1,4,5-trisphosphate [12]. Increased $\left[\mathrm{Ca}^{2+}\right]_{\mathrm{i}}$ causes phosphorylation of both the myosin light chain and pleckstrin to trigger $\delta$ - and $\alpha$-granule secretion and P-selectin expression. Therefore, decreasing intracellular calcium levels leads to the inhibition of platelet activation and aggregation. As shown in Fig. $3 \mathrm{~A}$ and $3 \mathrm{~B}$, EFA suppressed the collagen-induced $\left[\mathrm{Ca}^{2+}\right]_{i}$ level and serotonin release. $\mathrm{IP}_{3} \mathrm{RI}$ is a major substrate of protein kinase $A$ and protein kinase $\mathrm{G}$ in platelets, but its phosphorylation $\left(\mathrm{Ser}^{1756}\right)$ leads to the inhibition of $\left[\mathrm{Ca}^{2+}\right]_{\mathrm{i}}$ mobilization $[13,14]$. Therefore, this result indicates that the inhibition of $\left[\mathrm{Ca}^{2+}\right]_{i}$ levels by EFA is due to the elevation of $\mathrm{IP}_{3} \mathrm{RI}$ phosphorylation (Fig. 3C). $\mathrm{TXA}_{2}$ acts as a powerful autacoid that activates other platelets. Therefore, $\mathrm{TXA}_{2}$ production inhibitors are useful as anti-platelet substances; for example, aspirin, ozagrel, and indomethacin block $\mathrm{TXA}_{2}$ production by inhibiting cyclooxygenase-1 or TXA $\mathrm{T}_{2}$ synthase [15]. cPLA ${ }_{2}$ activation and $\left[\mathrm{Ca}^{2+}\right]_{\mathrm{i}}$ mobilization is essential for $\mathrm{TXA}_{2}$ production. Intracellular $\mathrm{Ca}^{2+}$ binds to $\mathrm{CLA}_{2}$, and activated $\mathrm{CPLA}_{2}$ is translocated from the cytosol to the membrane. Subsequently, p38 $8^{\mathrm{MAPK}}$ phosphorylates $\mathrm{CPLA}_{2}$ for full enzyme activity $[16,17]$. Therefore, inhibition of $\left[\mathrm{Ca}^{2+}\right]_{\mathrm{i}}$ mobilization and p3 $8^{\mathrm{MAPK}}$ phosphorylation leads downregulation of $\mathrm{TXA}_{2}$ production and we confirmed the relevance using specific inhibitors in a previous study $[18,19]$. EFA suppressed collagen-induced $\mathrm{TXA}_{2}$ production (Fig. 4A). This result indicates that the inhibition of $\mathrm{TXA}_{2}$ production by EFA is due to the decrease in $\left[\mathrm{Ca}^{2+}\right]_{i}$ levels 
and dephosphorylation of $\mathrm{CPLA}_{2}$ and $\mathrm{p} 38^{\mathrm{MAPK}}$ (Fig. 4B, C).

$\alpha \mathrm{IIb} / \beta 3$ is the most abundant integrin on the platelet surface and acquires the ability to bind to ligands such as fibrinogen, vitronectin, and fibronectin. $\alpha \mathrm{IIb} / \beta 3$ is expressed in a low-affinity state on resting platelets, and the inside-out signaling pathway initiates a conformational change within the receptor, which increases the affinity of $\alpha \mathrm{Ilb} / \beta 3$ to bind to ligands [3]. Upon fibrinogen binding, the receptor undergoes further shape changes, adhesion, and spreading. This process, termed outside-in signaling, results in platelet aggregation amplification. The effect of EFA upon fibrinogen binding was investigated using a fluorescenceactivated cell sorter. EFA suppressed collagen-induced fibrinogen binding and fibronectin adhesion (Fig. 5A, C). These results indicate that the decrease in $\alpha \mathrm{IIb} / \beta 3$ affinity caused by EFA is due to VASP $\left(\mathrm{Ser}^{157}, \mathrm{Ser}^{239}\right)$ phosphorylation and Akt $\left(\mathrm{Ser}^{473}\right)$ dephosphorylation (Fig. 6A, B) [20-22].

Intracellular cAMP and cGMP are reported to reverse platelet aggregation and are regulated by the balance between adenylate/ guanylate cyclase and phosphodiesterases [23]. These cyclic nucleotides can inhibit $\alpha \mathrm{IIb} / \beta 3$ activity and $\left[\mathrm{Ca}^{2+}\right]_{\mathrm{i}}$ mobilization through protein kinase A and protein kinase G [24]. In our study, EFA increased cAMP concentration (Fig. 6C), which enhanced the phosphorylation of VASP $\left(\mathrm{Ser}^{157}\right)$ and $\mathrm{IP}_{3} \mathrm{RI}\left(\mathrm{Ser}^{1756}\right)$. Insideout and outside-in signaling pathways lead to platelet activation and fibrin platelet meshwork development. Fibrin clot formation, which acts on the hemostasis of damaged blood vessels, creates a thrombus. The interaction between $\alpha \mathrm{IIb} / \beta 3$ and fibrinogen or fibronectin plays an important role in fibrin clot formation. As shown in Fig. 7, the EFA suppressed thrombin-induced fibrin clot formation. These results show that EFA is a potential potent antiplatelet agent through thrombus formation inhibition.

In conclusion, we confirmed that EFA decreases calcium mobilization, $\mathrm{TXA}_{2}$ production, fibrinogen binding to $\alpha \mathrm{IIb} / \beta 3$, fibronectin adhesion, and clot retraction through cAMP-dependent phosphorylation. Therefore, we suggest that EFA extracted from the root and stems of $C$. tricuspidata would be a useful compound for thrombosis prevention.

Acknowledgments This study was supported by a grant (NRF2018R1C1B5083580) from the Basic Science Research Program via the National Research Foundation of Korea (NRF), funded by the Ministry of Education, Science and Technology, Korea.

Conflict of interest The authors declare no conflict of interest.

\section{References}

1. Chen H, Kahn ML (2003) Reciprocal signaling by integrin and nonintegrin receptors during collagen activation of platelets. Mol Cell Biol 23: 4764-4777

2. Farndale RW (2006) Collagen-induced platelet activation. Blood Cell Mol Dis 36: 162-165

3. Phillips DR, Nannizzi-Alaimo L, Prasad KS (2001) Beta3 tyrosine phosphorylation in alphaIlbbeta3 (platelet membrane GP IIb-IIIa) outside-in integrin signaling. Thromb Haemost 86: 246-258

4. Andrews RK, Berndt MC (2004) Platelet physiology and thrombosis. Thromb Res 114: 447-453

5. Jackson SP (2011) Arterial thrombosis-insidious, unpredictable and deadly. Nat Med 17: 1423-1436

6. Kim DC, Yoon CS, Quang TH, Ko W, Kim JS, Oh H, Kim YC (2016) Prenylated flavonoids from Cudrania tricuspidata suppress lipopolysaccharideinduced neuroinflammatory activities in BV2 microglial cells. Int J Mol Sci 17:255

7. Xin LT, Yue SJ, Fan YC, Wu JS, Yan D, Guan HS, Wang CY (2017) Cudrania tricuspidata: an updated review on ethnomedicine, phytochemistry and pharmacology. RSC advances 7: 31807-31832

8. Shin JH, Ha JY, Kwon HW (2020) Inhibitory Actions of Steppogenin on Platelet Activity Through Regulation of Glycoprotein IIb/IIIa and $\mathrm{Ca}^{2+}$ Mobilization. Korean J Pharmacogn 51: 100-106

9. Shin JH (2020) Inhibitory Effects of Isoderrone on Platelet Aggregation through Regulation of Cyclic Nucleotides. J Korean Soc Food Sci Nutr 49: 796-802

10. Shin JH, Kwon HW, Lee DH (2019) Ginsenoside F4 inhibits platelet aggregation and thrombus formation by dephosphorylation of IP3RI and VASP. J Appl Biol Chem 62: 93-100

11. Grynkiewicz G, Poenie M, Tsien RY (1985) A new generation of $\mathrm{Ca}^{2+}$ indicators with greatly improved fluorescence properties. J Biol Chem 260: $3440-3450$

12. VargaSzabo D, Braun A, Nieswandt B (2009) Calcium signaling in platelets. J Thromb Haemost 7: 1057-1066

13. Quinton TM, Dean WL (1992) Cyclic AMP-dependent phosphorylation of the inositol-1,4,5-trisphosphate receptor inhibits $\mathrm{Ca}^{2+}$ release from platelet membranes. Biochem Bioph Res Co 184: 893-899

14. Cavallini L, Coassin M, Borean A, Alexandre A (1996) Prostacyclin and sodium nitroprusside inhibit the activity of the platelet inositol 1,4,5trisphosphate receptor and promote its phosphorylation. J Biol Chem 271: 5545-5551

15. Patrono C (1994) Aspirin as an antiplatelet drug. N Engl J Med 330: $1287-1294$

16. Kramer RM, Roberts EF, Um SL, Börsch-Haubold AG, Watson SP, Fisher MJ, Jakubowski JA (1996) p38 mitogen-activated protein kinase phosphorylates cytosolic phospholipase A2 (cPLA2) in thrombinstimulated platelets. evidence that proline-directed phosphorylation is not required for mobilization of arachidonic acid by cPLA2. J Biol Chem 271: 27723-27729

17. McNicol A, Shibou TS (1998) Translocation and phosphorylation of cytosolic phospholipase A2 in activated platelets. Thromb Res 92: 19-26

18. Kwon HW (2018) Inhibitory Effects of PD98059, SB203580, and $\mathrm{SP} 600125$ on $\alpha$-and $\delta$-granule Release and Intracellular $\mathrm{Ca}^{2+}$ Levels in Human Platelets. Biomed Sci Lett 24: 253-262

19. Shin JH, Kwon HW, Rhee MH, Park HJ (2019) Inhibitory effects of thromboxane A2 generation by ginsenoside Ro due to attenuation of cytosolic phospholipase A2 phosphorylation and arachidonic acid release. J Ginseng Res 43: 236-241

20. Laurent V, Loisel TP, Harbeck B, Wehman A, Gröbe L, Jockusch BM, Carlier MF (1999) Role of proteins of the Ena/VASP family in actinbased motility of Listeria monocytogenes. ýJ Cell Biol 144: 1245-1258

21. Sudo T, Ito H, Kimura Y (2003) Phosphorylation of the vasodilatorstimulated phosphoprotein (VASP) by the anti-platelet drug, cilostazol, in platelets. Platelets 14: 381-390

22. Woulfe DS (2010) Akt signaling in platelets and thrombosis. Expert review of hematology 3: 81-91

23. Schwarz UR, Walter U, Eigenthaler M (2001) Taming platelets with cyclic nucleotides. Biochem Pharmacol 62: 1153-1161

24. Smolenski A (2012) Novel roles of cAMP/cGMP-dependent signaling in platelets J Thromb Haemost 10: 167-176 